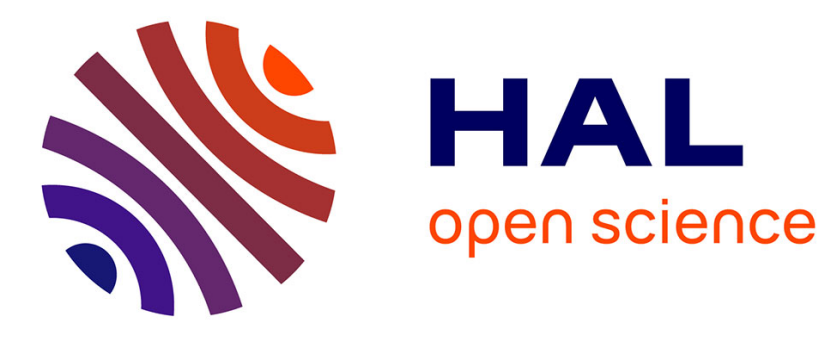

\title{
Unexpected dimerization of isoprene in a gas chromatography inlet. A study by gas chromatography/mass spectrometry coupling
}

Yannick Estevez, Christian Gardrat, Karine Berthelot, Etienne Grau, Bernard de Jéso, Samira Ouardad, Frédéric Peruch

\section{- To cite this version:}

Yannick Estevez, Christian Gardrat, Karine Berthelot, Etienne Grau, Bernard de Jéso, et al.. Unexpected dimerization of isoprene in a gas chromatography inlet. A study by gas chromatography/mass spectrometry coupling. Journal of Chromatography A, 2014, 1331, pp.133-138. 10.1016/j.chroma.2014.01.035 . hal-01368973

\section{HAL Id: hal-01368973 https://hal.science/hal-01368973}

Submitted on 26 Nov 2019

HAL is a multi-disciplinary open access archive for the deposit and dissemination of scientific research documents, whether they are published or not. The documents may come from teaching and research institutions in France or abroad, or from public or private research centers.
L'archive ouverte pluridisciplinaire HAL, est destinée au dépôt et à la diffusion de documents scientifiques de niveau recherche, publiés ou non, émanant des établissements d'enseignement et de recherche français ou étrangers, des laboratoires publics ou privés. 


\section{Unexpected dimerization of isoprene in a gas chromatography inlet. A study by gas chromatography/mass coupling spectrometry}

Yannick Estevez, Christian Gardra, Karine Berthelot, Etienne Grau, Bernard De Jeso, Samira Ouardad, Frédéric Peruch

\section{Abstract}

During analysis of pure isoprene by gas chromatography/mass spectrometry (GC-MS) using a programmed temperature vaporization (PTV) inlet, the presence of several isoprene dimers was detected in the total ion chromatograms (TICS). This study intends to determine the part of the instrument where dimerization occurs and the relative importance of the dimer amounts under different experimental conditions. The reference thermal dimerization of isoprene gives four six-membered cyclic dimers and two eight-membered ones. In all samples containing different amounts of freshly distilled isoprene, only peaks corresponding to the former appeared in TICS. For the same temperature, their amounts increase as the concentration of injected isoprene increases. The main products are diprene (from 80 to 100\%) of the total dimers and dipentene (from 1 to $14 \%$ ). The sum of the two other dimers is never higher than $6 \%$. In conclusion, isomeric dimers are produced through a dimerization in the inlet. No dimerization of isoprene occurs in the mass spectrometer source. Then care is needed when analyzing terpenic compounds in the presence of isoprene by GC-MS because structures, retention times and mass spectra of diprene and dipentene are close.

\section{Introduction}

Since a couple of years, we are studying the cationic polymerization of isoprene [1], [2], [3] and since more recently, we are investigating cascade enzymatic reactions dealing with terpene biosynthesis. As a consequence, the detection of isoprene, either its consumption for investigating the kinetics of polymerization reaction or its formation for enzymatic reactions is of great interest for us. Different methods for isoprene analysis are reported in the literature: detection of formaldehyde formed during reaction between ozone and isoprene by chemiluminescence [4], [5], Fourier-transform infrared photoacoustic spectroscopy (FTIR-PAS) [6], proton transfer reaction mass spectrometry (PTR-MS) [7], gas chromatography (GC) or coupling of gas chromatography with mass spectrometry under electron ionization (GC-EI-MS) [8], [9], [10], [11], [12].

During analysis of pure isoprene by GC-MS using a PTV inlet, we have detected the presence of several isoprene dimers. Although artifacts are well-known in chromatographic methods [13], it seems, to the best of our knowledge, that this particular phenomena has never been reported in the literature. It is known that isoprene, 
stored without a stabilizer, dimerizes very slowly at $20^{\circ} \mathrm{C}(0.000017 \%$ per hour $)$ [14], but more quickly at elevated temperatures $\left(0.023 \%\right.$ and $0.25 \%$ per hour at $60{ }^{\circ} \mathrm{C}$ and $100{ }^{\circ} \mathrm{C}$ respectively) [15]. Cycloaddition reactions of isoprene are well documented [16], [17], [18], [19], [20]. Isoprene may function both as a diene and a dienophile in cycloaddition reactions to form, in the absence of air and peroxides, four six-membered cyclic dimers: 1,5dimethyl-5-vinylcyclohex-1-ene, I; 1,4-dimethyl-4-vinylcyclohex-1-ene, II, 1-methyl-5-(prop-1-en-2-yl)cyclohex1-ene commonly called diprene or sylvestrene, III, 1-methyl-4-(prop-1-en-2-yl)cyclohex-1-ene also known as limonene or dipentene, IV; two other cycloaddition compounds, dimethyl-1,5-cyclooctadiene $\mathbf{V}$ and $\mathbf{V I}$, have also been detected in dimer mixtures (Table 1). Moreover, dimerization of isoprene has been observed in a mass spectrometer source [21].

Table 1. Structure and retention time $\left(t_{r}\right)$ of isoprene dimers.

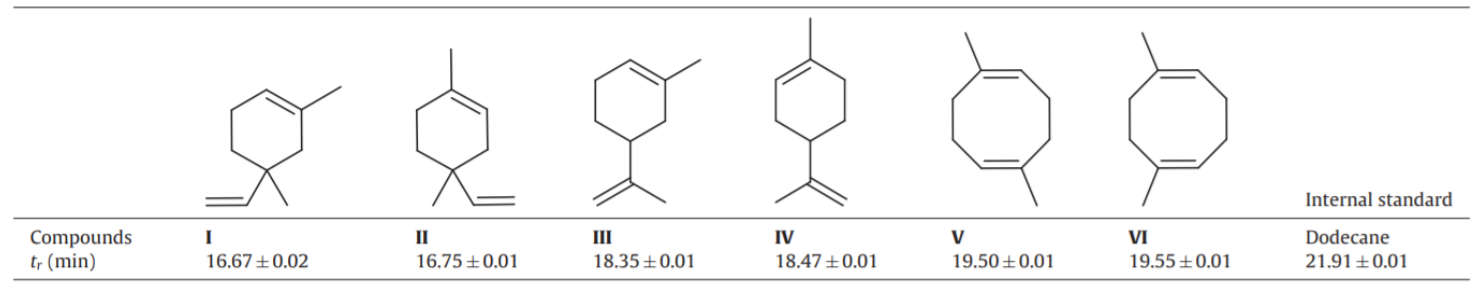

All these facts prompted us to investigate what was happening in our GC-MS system. This paper is dedicated to two main problems: (i) the part of the instrument where dimerization occurs and (ii) the relative importance of the dimer amounts.

\section{Materials and methods}

\subsection{Chemicals and reagents}

Isoprene (99\% Aldrich, Saint Quentin Fallavier, France) was distilled from $\mathrm{CaH}_{2}$ under an inert atmosphere prior to use. Heptane ( $\geq 99.5 \%$, Aldrich), $n$-dodecane ( $\geq 99.9 \%$ Merck, Nottingham, United Kingdom), $n$-pentane (Aldrich) and TEMPO (98\%, 2,2,6,6-tetramethyl 1-piperidin-N-oxyl radical, Aldrich) were used as received.

\subsection{Thermal dimerization of isoprene}

A mixture of isoprene dimers was prepared according to an already published method with small modifications [22]. Isoprene $(10 \mathrm{~g})$ thoroughly mixed with TEMPO (1 g) was introduced in a Parr 5100 reactor (Equilabo, Caluire et Cuire, France) for $2 \mathrm{~h}$ at $175^{\circ} \mathrm{C}$. After cooling, the dimer mixture was purified by column chromatography on silicagel 230/400 (Macherey-Nagel, Hoerdt, France) with pentane as eluent in order to remove impurities coming from TEMPO. 


\subsection{Isoprene solutions}

Freshly distilled isoprene $(1 \mu \mathrm{L}, 10 \mu \mathrm{L}, 20 \mu \mathrm{L}$ or $30 \mu \mathrm{L})$ was added to heptane using a $n$-dodecane solution $(1 \mu \mathrm{L})$ as an internal standard (IS) to obtain a total volume of $400 \mu \mathrm{L}$. The $n$-dodecane solution was obtained from pure $n$-dodecane $(4 \mu \mathrm{L})$ in heptane $(100 \mathrm{~mL})$. The volume of IS was fitted with the amounts of compounds of interest.

The same volume $(1 \mu \mathrm{L} \pm 1 \%)$ was injected using a CTC Analytics Combi Pal sampler (Alpha Mos, Toulouse, France).

The results were expressed as the mass of dimers per microliter of the initial isoprene solution (IS amount: $75 \mathrm{pg} / \mu \mathrm{L}$ of injected isoprene solution).

\subsection{GC-EI-MS analyses}

GC-EI-MS analyses were performed with a Finnigan Trace (ThermoFisher Scientific, Courtaboeuf, France) mass spectrometer (positive ion mode, electron energy $70 \mathrm{eV}$ ) interfaced with a Finnigan Trace GC Ultra Gas (ThermoFisher Scientific, Courtaboeuf, France) with a transfer line temperature hold at $250{ }^{\circ} \mathrm{C}$; helium was used as the carrier gas (constant flow, $1 \mathrm{~mL} / \mathrm{min}$ ). The ion source temperature was fixed at $200^{\circ} \mathrm{C}$. The apparatus was equipped with a programmed temperature vaporizer (PTV) inlet with a silcosteel liner (1.3 mm i.d.) (ThermoFisher Scientific, Courtaboeuf, France; catalog number 45322046). Different conditions were run: the inlet was used mainly in a splitless mode at four different constant temperatures $\left(150,200,250\right.$ or $\left.300{ }^{\circ} \mathrm{C}\right)$; some experiments were conducted in a split mode $(30 \mathrm{~mL} / \mathrm{min})$ at $300^{\circ} \mathrm{C}$; also, a temperature programmation from $80{ }^{\circ} \mathrm{C}$ to $300^{\circ} \mathrm{C}$ at $14.5^{\circ} \mathrm{C} / \mathrm{s}$ was performed in a splitless mode.

Chromatographic separations were performed with a wall-coated open tubular (WCOT) fused silica capillary column (VF-624 ms, 30 m, 0.25 mm i.d., film thickness $1.40 \mu \mathrm{m}$ ). The oven temperature was programmed from $32{ }^{\circ} \mathrm{C}$ (initial hold time of $5 \mathrm{~min}$ ) to $200^{\circ} \mathrm{C}$ at a rate of $7.5^{\circ} \mathrm{C} / \mathrm{min}$; the final temperature was maintained for $5 \mathrm{~min}$. Total ion chromatograms (TICS) were recorded (full scan range from $\mathrm{m} / \mathrm{z} 33$ to $\mathrm{m} / \mathrm{z} 500$ at $1.05 \mathrm{scan} \mathrm{s}^{-1}$ or selected ion monitoring at $\mathrm{m} / \mathrm{z} 136$ ) and treated (retention times, areas) with Excalibur 1.4 software. NIST 2.0 library was incorporated in the software.

\subsection{Statistics}

All experiments implying isoprene were triplicated. One-way ANOVA tests were made on all the data (PTV temperature, isoprene amounts) with a significance level defined at $p \leq 0.05$.

\section{Results and discussion}




\subsection{Preparation and identification of isoprene dimers}

In order to identify all isoprene dimers, a mixture of these compounds was prepared by thermal dimerization of isoprene in the presence of TEMPO to avoid polymerization (see experimental part). The TIC part corresponding to the products obtained after elimination of impurities coming from TEMPO along with the result of selected ion monitoring (SIM) for $m / z 136$ (dimer molecular masses) are respectively represented in Fig. $1 a$ and b. Six dimer peaks (1-6) appeared, which were attributed to compounds (I-VI) using literature [16], [17], [18] and NIST library (Table 1). Moreover, it is noteworthy that no differences appeared in retention times and compounds areas before (TIC not shown) and after purification. 

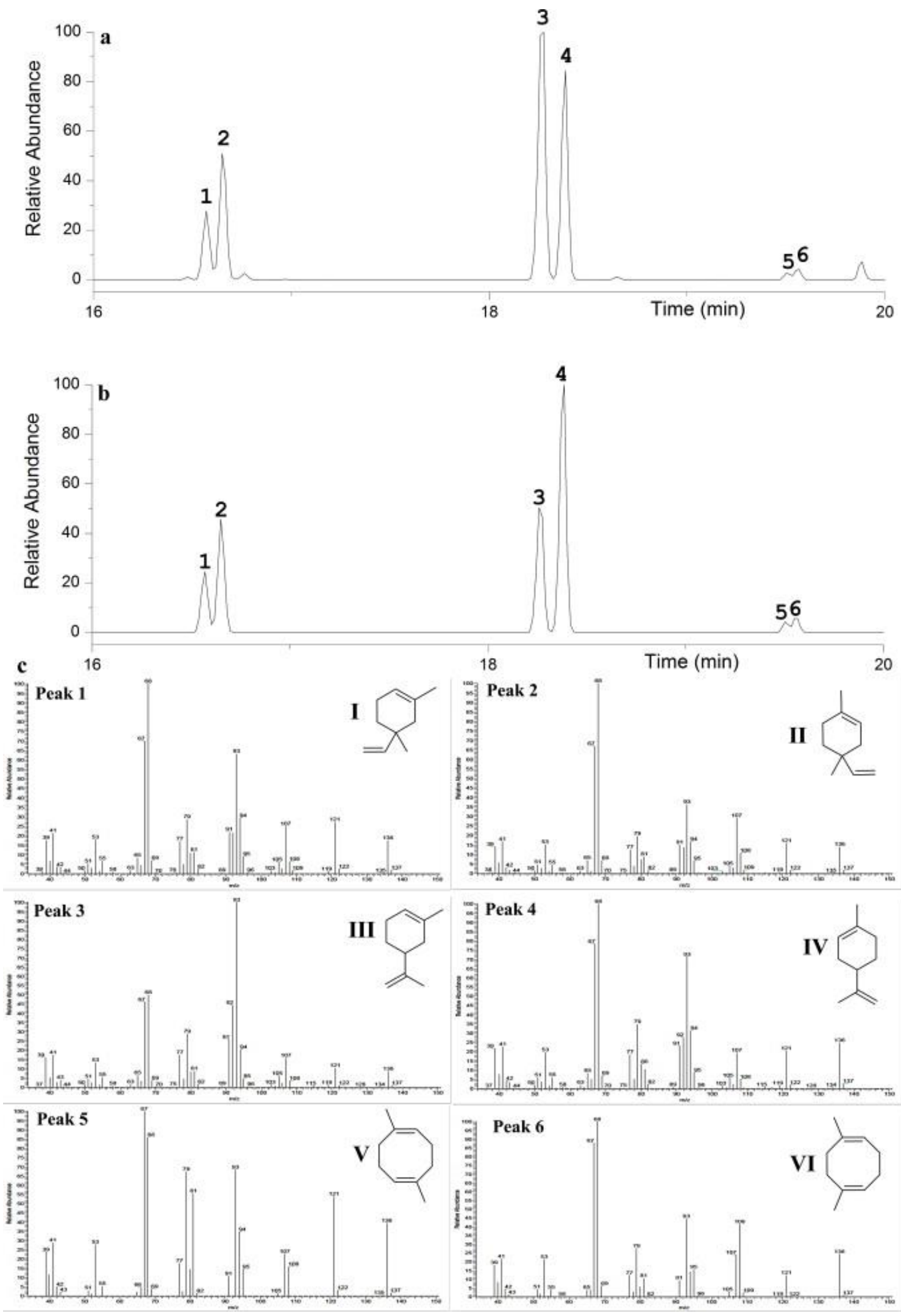

Fig. 1. Mixture of isoprene dimers formed under thermal conditions (see the experimental part). (a) TIC, (b) $\operatorname{SIM~(~} \mathrm{m} / \mathrm{z} 136)$, (c) mass spectrum of the compounds (I-VI). The peak numbers (1-6) fit respectively to compounds (I-VI). 
Differences between peak areas (TIC vs. SIM) are likely due to differences in the relative abundances of molecular peaks of the dimers (18\% for I, $14 \%$ for II, $7 \%$ for III, $25 \%$ for IV, $40 \%$ for V and $24 \%$ for VI) represented in Fig. 1 c. A comparison of the peak area ratios of isoprene dimers which have similar structures with those reported in literature was presented in Table 2. Even if the reaction temperatures were different, almost the same results were obtained.

Table 2. Comparison of the ratios of isoprene dimers formed under thermal conditions.

$\begin{array}{lllll}\text { References } & \text { Temperature }\left({ }^{\circ} \mathrm{C}\right) & \text { Peak 1/peak 2 I/II } & \text { Peak 3/peak 4 III/IV } & \text { Peak 5/peak 6 V/VI } \\ {[17]} & 115 & 1 / 2.3 & 1.6 / 1 & 1 / 2.1 \\ {[18]} & 120 & 1 / 2.0 & 1.7 / 1 & 1 / 1.9 \\ \text { This work } & 175 & 1 / 1.9 & 1.4 / 1 & 1 / 1.6\end{array}$

The dimers were tentatively separated by several chromatographic techniques (TLC, silicagel column), but all methods failed; only impure mixtures were isolated in very small quantities. The same problem was encountered by Duschek et al. [17] who have isolated mixtures of compounds I-II, III-IV and V-VI by preparative gas chromatography.

\subsection{Dimerization of isoprene in GC-MS apparatus}

To have a better knowledge of isoprene dimerization in the apparatus, the inlet was used as a micro-reactor with different amounts of isoprene in solution. Isoprene and the solvent (heptane) are quickly eluted from the column (before $14 \mathrm{~min}$ ). The dimers appeared between 16 and $20 \mathrm{~min}$. Samples containing different amounts of isoprene were analyzed at four constant different temperatures of the inlet in splitless mode as described in the experimental part. Peaks corresponding to isoprene dimers appeared in all TICs, except for the smaller amount of isoprene $(1 \mu \mathrm{L})$, even for the highest temperature $\left(300^{\circ} \mathrm{C}\right)$. All results are reported in Fig. $2 \mathrm{a}(\mathrm{A}-\mathrm{C})$, assuming that the area of each dimer can be directly related to the area of the internal standard and consequently to the mass of the internal standard. As an example, the dimer zones of TICs for different amounts of isoprene (A: $30 \mu \mathrm{L}$, B: $20 \mu \mathrm{L}$ and $\mathrm{C}: 10 \mu \mathrm{L})$ are represented in Fig. $2 \mathrm{~b}(\mathrm{~A}-\mathrm{C})$ for a particular temperature of the inlet $\left(300^{\circ} \mathrm{C}\right)$ along with the thermal TIC of dimers (D) obtained in thermal conditions (vide supra) to have a better comparison. Dimers were formed also when using the inlet in the split mode or with a temperature programmation (data not shown). 

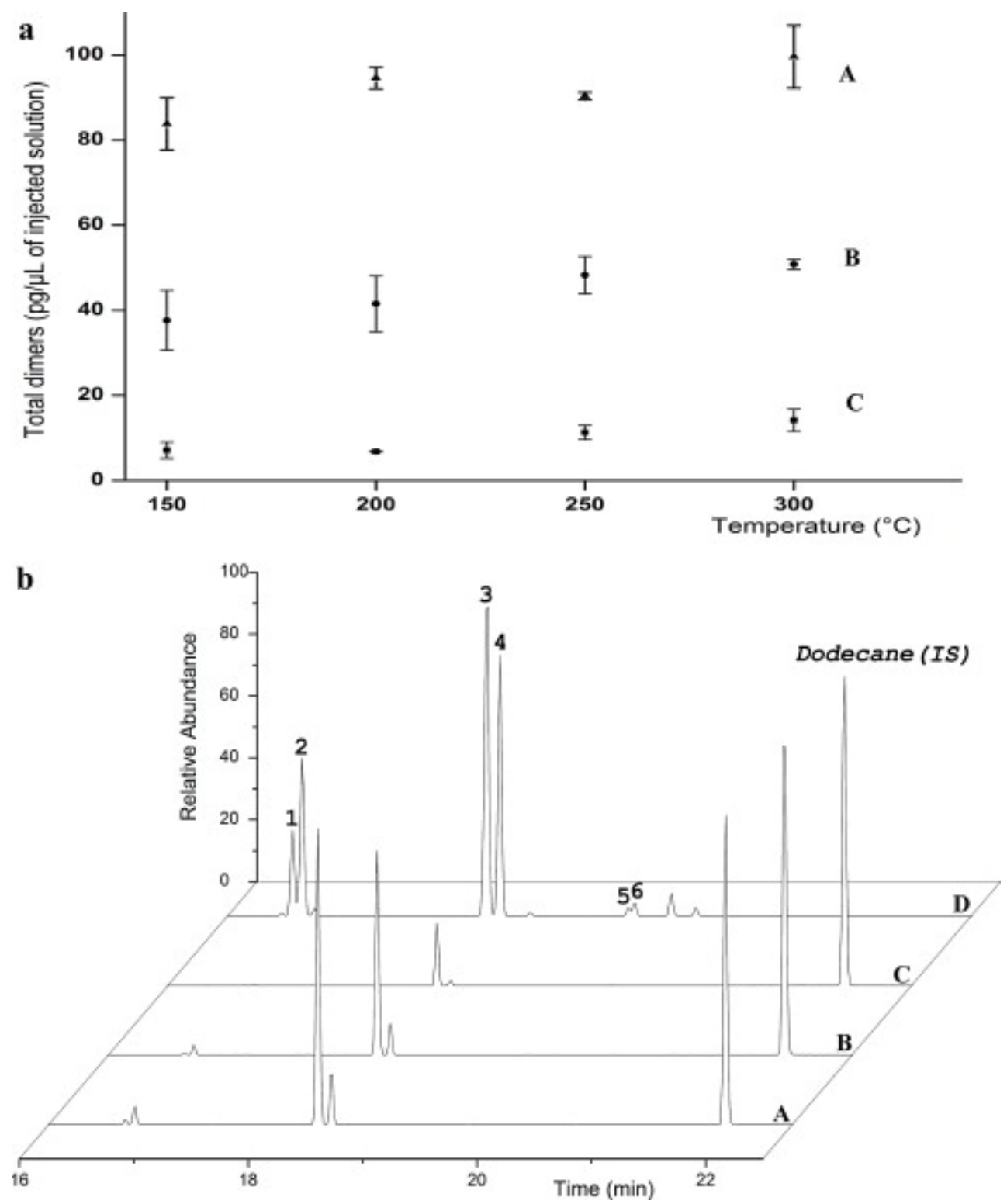

Fig. 2. Isoprene dimers formed in the PTV inlet (mean of three experiments). (a) Total dimer amounts (pg/ $\mu \mathrm{L}$ of injected isoprene solution) vs. PTV inlet temperatures and isoprene quantities. (b) TICs of isoprene dimers formed in the PTV inlet at $300^{\circ} \mathrm{C}$. Isoprene amounts in the initial solution $(\mu \mathrm{L}) \mathrm{A}: 30 ; \mathrm{B}$ : 20; C: 10; D: TIC of a reference dimer mixture obtained under thermal conditions (see the experimental part).

\subsection{Total dimer amounts}

Only four dimers (I-IV) were formed. In the chosen experimental conditions (isoprene concentrations and PTV temperatures), cyclooctadienes (V-VI) never appeared in TICs. Fig. 2a indicated different tendencies: for the same temperature, the amounts of dimers increased with the concentration of injected isoprene in a nonproportional way and differences are statistically significant $(p<0.01)$; for the same concentration, a very slight increase of the total amounts of dimers occurred as the temperature increased, but the slopes are very small 
$(0.040 \pm 0.004$ for $10 \mu \mathrm{L}, 0.09 \pm 0.01$ for $20 \mu \mathrm{L}$ and $0.09 \pm 0.02$ for $30 \mu \mathrm{L})$ and differences are not statistically significant $(p>0.05)$.

\subsection{Relative ratios of dimers}

The relative ratios of all dimers were presented in Fig. 3a and $b$. The main products are diprene III and dipentene IV; the former was always the most abundant (from 80 to $100 \%$ of the total dimers). With a temperature increase, other dimers were formed and the amount of dipentene IV and of the other dimers I and II increased. Dipentene IV was always the second main product of the reaction (1-14\% of the total dimers). The sum of I and II was never higher than $6 \%$ of the total dimers. For the same amount of isoprene, each dimer quantity seemed to increase as the temperature increases, but there is no evident significance $(p>0.05)$; the total amount of diprene and dipentene goes between 94 and $100 \%$ of the total dimers. For the same temperature, the amount of each dimer increased as the amount of isoprene increased $(p<0.01)$. A rise of the temperature or the amount of isoprene favors the formation of dipentene to the detriment of diprene. A comparison between dimers I and II did not seem pertinent as their respective and total amounts were too small. 

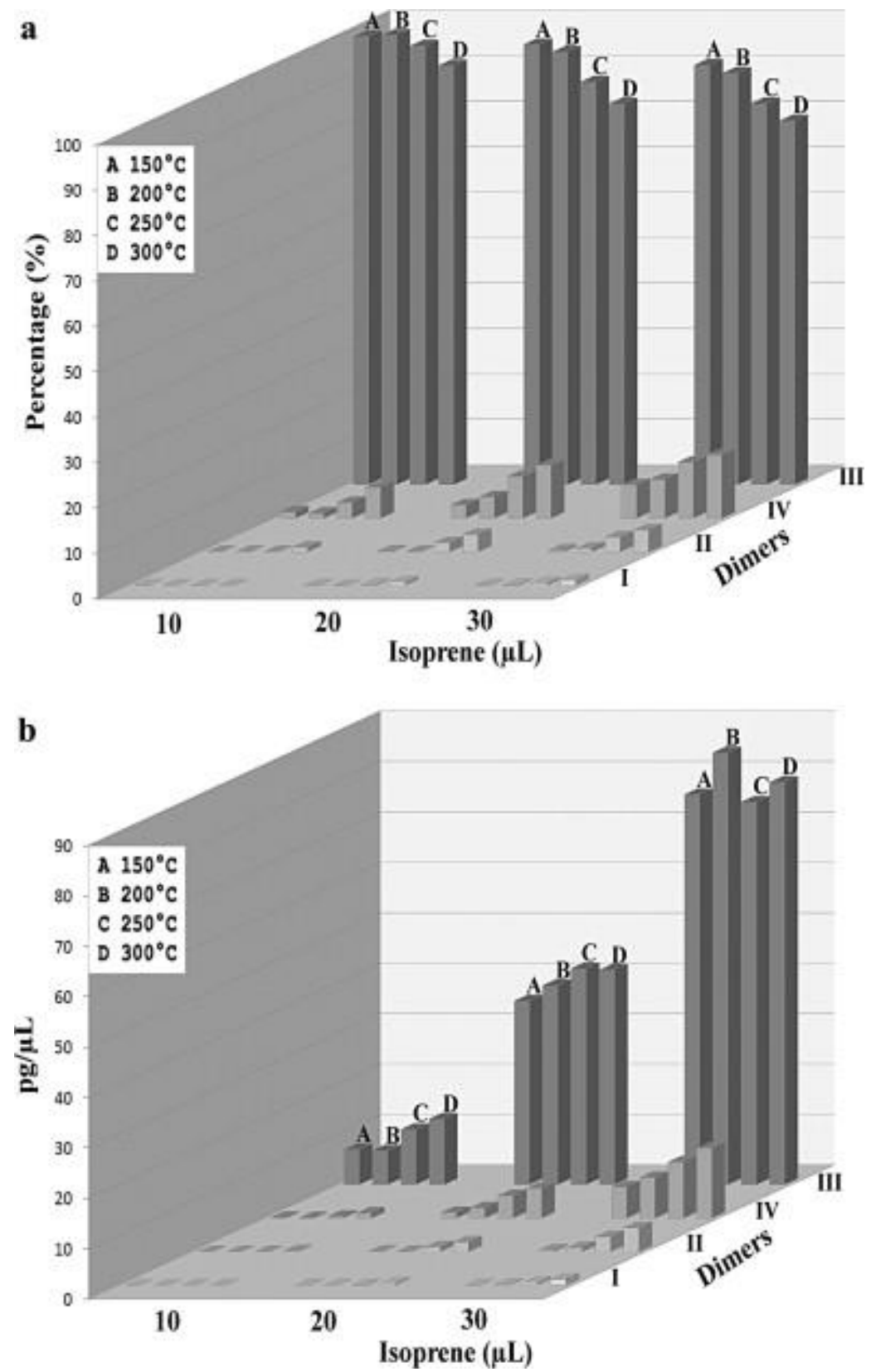

Fig. 3. Production of dimers formed in the PTV injector at different temperatures and different isoprene amounts (mean of three experiments). (a) Relative dimer proportions (\%). (b) Production amounts of dimers $(\mathrm{pg} / \mu \mathrm{L})$.

The relative ratios of isoprene dimers were not in accordance with the results already described in the literature [17], [19], [20], [22]. If III was generally the major compound at temperatures under $200{ }^{\circ} \mathrm{C}$ [17], [19], [20], [22], IV may be formed in higher amounts at temperatures above $200{ }^{\circ} \mathrm{C}[19],[20]$. Moreover, I and II were obtained in larger proportions ( $\gg 20 \%$ ) [17], [19], [20], [22], and V and VI were always formed (often $>10 \%$ ). In this study, substituted cyclooctadiene isomers $\mathbf{V}$ and $\mathbf{V I}$ were never detected under all the experimental conditions described above. No explanation of this fact can be given. 


\subsection{Interpretation of the results}

All experiments show that the isomeric dimers are produced through a dimerization reaction which occurs during the slow transfer process in the PTV inlet and not during the fast process of injection from the syringe. Production of dimers along the column is to be excluded because dimer peaks are very sharp (see Fig. $2 \mathrm{~b}$ ) and not enlarged. It should be noticed that, in the mass spectrum of the non-reacted isoprene which is always present, no peak appeared at $m / z 136$, indicating that there is no dimerization of the compound in the mass spectrometer source. Isoprene presents itself as a mixture of S-cis and S-trans conformers in planar or gauche geometries. According to literature [23], isoprene molecules are mainly in the S-trans conformation: calculations indicate that, at $25^{\circ} \mathrm{C}$ the cis-conformer constitutes only $\sim 11 \%$ of the population, $\sim 17 \%$ at $125{ }^{\circ} \mathrm{C}, \sim 21 \%$ at $225^{\circ} \mathrm{C}$ and $\sim 24 \%$ at $325^{\circ} \mathrm{C}$. Nevertheless, the barrier to rotation is small and access to the more reactive $S$-cis conformer is easy [24], [25]. The formation of six-membered ring products seems to imply a $[4 \pi+2 \pi]$ concerted cycloaddition in the gas phase (Diels-Alder reaction). The two double bonds of isoprene acting as diene must be in the $S$-cis conformation and the isoprene acting as dienophile may have either S-cis or S-trans conformations. The formation of the two main compounds III and IV can be explained by the frontier orbitals theory [26], [27], [28]. According to the latter applied to Diels-Alder reactions, the interaction between the diene HOMO (highest occupied molecular orbital) and the dienophile LUMO (lowest unoccupied molecular orbital) is favored, leading, in the case of the reaction of isoprene with itself, to a major compound, diprene III and to a minor one, dipentene IV. An increase in temperature reduces the selectivity of the reaction leading to the formation of more dipentene IV. Nevertheless, the formation of compounds I and II, which is allowed by symmetry, cannot be so easily explained. $A b$ initio analysis of the Diels-Alder reaction between two isoprenes implying all possible orientations of the molecules during their dimerization was recently published [29]. Depending on the relative approaches of both isoprene molecules, either a cyclic monoterpene is obtained via a concerted Diels-Alder pathway leading to four kinds of compounds (I-IV) with different enantiomers and conformational isomers, either a diradical open-chain intermediate is formed to give compounds by a stepwise pathway. It seems interesting to note that the latter mechanism was proposed in the dimerization of chloroprene to form a compound similar to I and II [28]. Although calculations cannot describe diradical and non-radical relative origins of the compounds, the concerted pathways are kinetically more favored than the stepwise ones [24]. 


\section{Conclusions}

Dimerization of isoprene can occur in gas chromatography inlets. The dimer amount mainly depends on the concentration: at relatively low concentrations, the conversion is low but it increases as the concentration increases. The repartition of the different isomers depends also on the isoprene concentration. Diprene is always the major compound followed by dipentene. As the structures of sylvestrene and dipentene are similar, their retention times and their mass spectra are close, the analysis of a mixture of terpenic compounds containing isoprene by GC-MS may present attribution difficulties.

\section{Acknowledgements}

YE and KB acknowledge the "Agence Nationale pour la Recherche" for their Post-Doctoral Researcher Fellowship (ANR Polyterp; ANR-10-CD2I-08). The authors thank Msc Cristian Valencia of the Instituto de Medicina Tropical "Alexander von Humboldt" Universidad Peruana Cayetano Heredia (UPCH), Lima, Peru for his constructive criticisms.

\section{References}

[1] S. Ouardad, A. Deffieux, F. Peruch, Polym. Chem., 4 (2013), p. 1874

[2] S. Ouardad, T. Lebarbé, A. Deffieux, F. Peruch, Polym. Chem., 4 (2013), p. 407

[3] S.V. Kostjuk, S. Ouardad, F. Peruch, A. Deffieux, C. Absalon, J.E. Puskas, F. Ganachaud, Macromolecules, 44 (2011), p. 1372

[4] A.J. Hills, P.R. Zimmerman, Anal. Chem., 62 (1990), p. 1055

[5] S.E. Weise, Z. Li, A.E. Sutter, A. Corrion, A. Banerjee, T.D. Sharkey, Anal. Biochem., 435 (2013), p. 27

[6] F. Kühnemann, M. Wolfertz, S. Arnold, M. Lagemann, A. Popp, G. Schüler, A. Jux, W. Boland, Appl. Phys. B, 75 (2002), p. 397

[7] T. Karl, R. Fall, T. Rosenstiel, P. Prazeller, B. Larsen, G. Seufert, W. Lindinger, Planta, 215 (2002), p. 894

[8] G. Arh, L. Klasinc, M. Veber, M. Pompe, Chromatogr. J. A, 1218 (2011), p. 1538

[9] K.M. Cooke, S. Hassoun, S.M. Saunders, M.J. Pilling, Chemosphere Global Change Sci., 3 (2001), p. 249

[10] A.C. Lewis, K.D. Bartle, J.B. McQuaid, M.J. Pilling, P.W. Seakins, P. Ridgeon, J. High Resolut. Chromatogr., 19 (1996), p. 686

[11] A.C. Lewis, K.D. Bartle, L. Rattner, Environ. Sci. Technol., 31 (1997), p. 3209

[12] A.C. Lewis, P.W. Seakins, A.M. Denha, K.D. Bartle, M.J. Pilling, Atmos. Environ., 29 (1995), p. 1871

[13] B.S. Middleditch, Analytical Artifacts: GC, MS, HPLC, TLC and PC (Journal of Chromatography Library), Elsevier, Amsterdam, New York (1989)

[14] K.I. Sakodynskii, Gazov. Khromatogr., 190 (1969), (Chem. Abstr. 1970:11960)

[15] W.M. Saltman, M. Grayson, D. Eckroth (Eds.), Kirk-Othmer Encyclopedia of Chemical Technology (3rd ed.), Wiley-Interscience, New York (1981), p. 818

[16] M. Citroni, M. Ceppatelli, R. Bini, V. Schettino, J. Phys. Chem. B, 111 (2007), p. 3910

[17] C. Duschek, W. Höbold, W. Pritzkow, B. Rothenhäusser, H. Schmidt, W. Engler, D. Estel, H.G. Hauthal, J. Korn, G. Zimmermann, J. Prakt. Chem. (Leipzig), 312 (1970), p. 15

[18] J.K.J. Krupka, Pet. Coal, 54 (2012), p. 385

[19] I.N. Nazarov, A.I. Kuznetsova, N.V. Kuznetsov, Zh. Obshch. Khim., 25 (1955), p. 307

[20] C. Walling, J. Peisach, J. Am. Chem. Soc., 80 (1958), 5819 and cited references

[21] S. Groves, R. Lehrle, Polym. Degrad. Stab., 38 (1992), p. 183

[22] H.A. Colvin, American Patent US 4973787 (1990).

[23] D.A.C. Compton, W.O. George, W.F. Maddams, J. Chem. Soc., Perkin Trans., 2 (1976), p. 1666

[24] C.W. Bock, Y.N. Panchenko, S.V. Krasnoshchiokov, R. Aroca, J. Mol. Struct., 160 (1987), p. 337

[25] M.E. Squillacote, F. Liang, J. Org. Chem., 70 (2005), p. 6564

[26] I. Fleming, Frontier Orbitals and Organic Reactions, Wiley, London (1976)

[27] K.N. Houk J. Am. Chem. Soc., 95 (1973), p. 4092

[28] R. Bruckner, M. Harmata (Ed.), Organic Mechanisms - Reactions, Stereochemistry and Synthesis, Springer-Verlag, Berlin, Heidelberg (2010), p. 643

[29] C.-M. Wang, Z.-H. Liu, Y.-K. Chen, J.-M. Han, Y.-L. Chen, M.-M. Miao, H. Cao Comput. Theor. Chem., 1017 (2013), p. 174 